\title{
Factor model of social media marketing effect on brand loyalty
}

\author{
Olga Chubukova ${ }^{1}$, Iuliia Kostynets $^{2, *}$, Igor Ponomarenko ${ }^{1}$, Nataliia Rallie $^{1}$, and Yuliia Zymbalevska ${ }^{1}$
}

${ }^{1}$ Kyiv National University of Technology and Design, Department of Economic Cybernetics and Marketing, 2, Nemirovycha-Danchenko str., Kyiv, 01011, Ukraine

${ }^{2}$ National Academy of Management, Department of Marketing, Economics, Management and Administration, 15, Ushynskogo str., Kyiv, 03151, Ukraine

\begin{abstract}
This research presents the model regarding core factors of social media marketing effect on brand loyalty. The conceptual model was defined based on the five hypotheses. It was conducted a reliability analysis based on the internal consistency of measurements, using Cronbach Alpha and composite reliability coefficients. The model shows that the characteristics of social media marketing communications have a direct effect on brand trust and brand affect. It also demonstrates that brand trust has a direct effect on brand affect and on brand loyalty. Brand affect has also a direct effect on brand loyalty. The research demonstrated that social media marketing communication has the capacity to influence brand trust and brand affect, the two main determinants of brand loyalty. The model shows that the characteristics of social media marketing communications have a direct effect on brand trust and brand affect. It also demonstrates that brand trust has a direct effect on brand affect and on brand loyalty. Brand affect has also a direct effect on brand loyalty. Therefore, all five research hypotheses were validated. The implications for marketing theory and practice are discussed, and avenues for future research are proposed.
\end{abstract}

\section{Introduction}

In the conditions of active integration of a large population to the Internet and its involvement in social networks, a new kind of marketing has emerged - social media marketing. Evolution of views of users of the global network and the transformation of social networks in conditions of significant competition between them requires continuous monitoring of these services and changing the behavioral models of the relevant groups of users to optimize the marketing strategies of companies.

Social media marketing is based on social ecosystem that makes possible to identify the peculiarities of constructing structural interactions in certain communities of the digital environment and to use them in the process of developing relevant marketing strategies.

\section{Literature review}

Evans and McKee distinguished three main elements of the social ecosystem (Fig. 1).

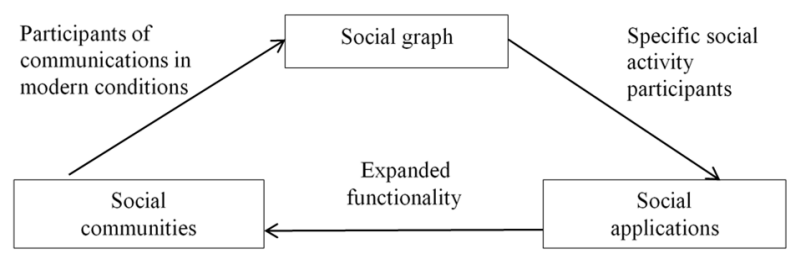

Fig. 1. Social ecosystem [3].
1. Social graph is a connecting element that makes it possible to link the profiles of certain users to each other and track any changes that occur as a result of adding or editing relevant content to affiliated users. The algorithm of social networking software enables to identify people close by certain signs who are likely to be interested in joining a certain thematic community according to the concept of a social graph. This approach is actively used by companies to combine a target group with specialized communities that provides certain thematic content to form users at a certain stage of communication loyalty to a particular brand.

2. Social applications are tools for expanding key social platform opportunities and program services that function in the specifics of certain social networks and allow users to gain additional opportunities in certain functional areas. Increasing the number of applications and expanding their functionality in accordance with modern society demands makes them more attractive to specific groups of users, which in general positively affects the popularity of individual social networks [1].

The effectiveness of social applications has led them to be actively used by individual companies for marketing purposes, since these tools provide an opportunity to increase the quantitative and qualitative characteristics of the relationship between the brand and the audience. The introduction of modern approaches to digital marketing enables us to develop a communications system to the level of an individual user, providing personalized content in accordance with the concept of the avatar. The scientifically grounded development of specialized applications in conjunction with relevant marketing approaches enables the creation

\footnotetext{
* Corresponding author: yulia.kostinets@gmai.com
} 
of thematic social groups that will be of great popularity among the audience as a result of its awareness of a certain consumer value.

3. Social communities are groups of users who create groups in certain social networks based on individual interests, attitudes to life, professional specifics and other social, demographic and economic characteristics, which in this case play a key role. An important role in these communities is given to the support of its members (forums, FAQs, information services, etc.). The success of the company's operation in social networks is characterized by the effectiveness of its work in the areas of development of the communities and infrastructure.

The specificity of functioning in social networks enables companies to contact users to use such communications as:

- creation of specialized groups in social networks and filling them with relevant content, which allows to build a specific sales funnel, gradually warm up the target audience, bringing it to the purchase of certain goods or services;

- organizing thematic events sponsored by the company, enabling it to form a positive reputation for the target audience, which can be used at certain times as a tool for selling the product of the brand;

- filing in the form of news advertising information about company products, etc. [2].

Nowadays the consumers' loyalty towards their brands represents a significant competitive advantage with strong effects on their commercial success. The researches demonstrates that loyal customers are willing to purchase more frequently, spend money on trying new products or services, recommend products and services to others, and give companies sincere suggestions. Also the consumers' loyalty creates entry barriers for competing brands, gives the company time to react on competitors innovations, makes it possible to charge higher prices and it also functions as a buffer in times of intense price competition, generate long term customer retention, reduce marketing costs and lead to a greater market share.

Consumer loyalty is a declared goal for many organizations and remains central in order to increase market share and profits. However, a substantial number of consumers seems to be loyal to not just one, but several brands.

Jacoby and Kyner described loyalty as "a biased behavioral response expressed over time by a decision making unit with respect to one or more alternative brands out of a set of brands and being a function of psychological processes [3-5].

Therefore, the companies are implementing marketing strategies in order to develop, maintain or enhance customer loyalty using different tools and techniques. One of the main marketing communication strategies that are being used nowadays in order to build brands is related to the usage of social media.

\section{Materials and methods}

Features of building communications in the marketing of social networks involve the involvement of such agents of influence:

1. Hidden agents of influence by means of indirect methods form a positive impression on the company as a whole or on its specific products in the target audience. When communicating, social networking users perceive these agents as ordinary people who are also interested in certain topics, share objective information, share their thoughts and give advice as if based on the personal experience of using a certain brand of products.

2. Open influence agents implement a set of events of image-oriented nature, aimed at openly promoting the company from its own name, demonstration to other users of their own positive attitude towards the brand and leveling the negative attitude of individual groups of consumers.

3. Star agents of influence are those who have gained some popularity in society as a whole or in certain social groups of the population and can be used to promote the brand. Among the mentioned agents it is expedient to allocate the following groups:

- representatives of creative professions that have gained some popularity in the show business (actors, singers, models, etc.);

- specialists in certain types of activities that have become popular (fitness trainers, designers, doctors, etc.);

- bloggers and others. In the implementation of marketing strategies actively used advertising, which in the digital environment has certain features.

It's advisable to use targeted advertising in social media marketing.

The main advantages of this approach are:

1. The company creates its own page in a social network, which hosts a variety of information about its own products, as well as related content. In this case, the costs of the company are much smaller, compared with the creation of the site.

2. It is possible to customize filters to select the target audience, which will display certain content of the company in the social network. Segmentation can be carried out on a wide range of features, among which the key is the territorial placement, gender, age group, interests.

3. Social networks allow you to create a variety of groups that will involve interest-specific users with specific content requirements. A specific target group within the group may display relevant contextual advertising.

4. Specificity of creating profiles in social networks leads to the publication of part of the users own contact data (mobile phone number, email address). Based on this information, it is possible to customize the company's contextual advertising. It should be noted that it is possible to obtain information about social network users that is confidential, due to the use of web scraping technology (parsing sites). The above-mentioned technology allows at the code level to filter information and to allocate personal data of individual users without taking into account their interests. A large number of companies use web scrapping despite its illegality. 
Various communication channels are used to maximize the involvement of users in social networks in the profile of the company and the formation of its positive perception. Among the factors that influence the increase of loyalty of the target audience to the brand, an important place is taken by motivational measures that have both material and immaterial character. Due to the introduction of competitions, the company has the opportunity to raise awareness of its products, which enables communication to be enhanced and increases the likelihood of the target audience purchasing the goods or services in question. The most widespread in modern conditions of drawings include:

1. Toilet. The company organizes a certain event, which involves the target audience and actively participates in this event by distributing certain information about the brand (to put a name, make a repo, etc.). The winner will be determined by the method of random selection among the participants of the event.

2. Quiz. The purpose of this event is to create the preconditions for familiarizing the target audience with information about the company, its products, social activity, etc. on a motivational basis. In this case, users have the opportunity to receive a certain reward for demonstration of knowledge about the company. The tool is often used when a new product is launched on the market.

3. Rewarding active users. At certain intervals (week, month, year) the company determines the participants who are active by placing a certain number of comments, likes, repos, etc. In this case, most of the prizes are symbolic (souvenir products), but this kind of motivation is aimed at showing the brand's attention to its own target audience and value for its clients.

4. Offline activity. This method is very complex in its essence, because it involves the target audience performing a certain list of actions outside the Internet with the effort, but the company eventually receives a long-lasting effect (for example, to visit certain cultural or historical places and distinguish there (named "checkin").

5. hoto contests. In modern conditions, a significant number of people publishes pictures in social networks. The subject matter of the photos depends on the age group, socio-demographic characteristics, the range of interests and other factors. Among social networks, Instagram has a special place in posting photos, which allows you to quickly upload photos and share them with friends. The company can use it for a photo competition, which is announced in a particular group, located in the social network [6].

To implement a campaign in a social network, you need to do the following:

1. Identify the tactical and strategic goals that the company plans to achieve in the social network;

2. Identify key features that will be segmented by the audience;

3. Conduct a comprehensive analysis of existing social networks and identify networks in which it is expedient to implement the marketing strategy of the company;
4. Create company profiles in selected social networks and fill them with relevant content that takes into account the specifics of each of the networks;

5. Join the specialized groups whose topics correspond to the company's specialization, and the target audience belongs to the category of potential clients;

6. Constantly monitor the activity of the target audience, change its interests, topics for discussion, determine the optimal delivery of content for a particular social network in the appropriate period of time and on the basis of the results, appropriately, with clearly defined periodicity, to fill out the information page of the company;

7. To substantiate the system of key performance indicators (KPIs) that will assess the effectiveness of a campaign's performance in a particular social network;

8. Identify the employees responsible for the company who will deal with the issues of implementation of the marketing strategy in social networks or delegate the corresponding functions to another specialized company on the terms of outsourcing;

9. Calculate the planned budget for the launch and implementation of the campaign in the relevant social network [7].

All companies can create close relationships with their customers in the virtual environment of social media. Social media marketing can lead to a higher consumers' involvement with their brands. Therefore, the research presented in this paper aims to study the influence of social media marketing communication on brand loyalty and its main determinants: brand trust and brand affect.

Brand trust can be defined as a consumer's willingness to rely on the brand in the face of risk because of expectations that the brand will cause positive outcomes. In order to build trust, products or services must always meet or even exceed the consumers' expectations.

Brand affect is a concept that reflects the consumer's emotional involvement towards a brand, due to the fact that the brand acts as an important reflection of selfidentity or is an important symbol of something meaningful to the consumer.

\section{Results and discussion}

The conceptual model regarding the influence of social media marketing communication on brand trust, brand affect and brand loyalty includes four variables. The variable social media marketing communication was defined as a formative variable and it was measured through 10 items, using a 7-point semantic differential, from 1-completely unimportant to 7-extremely important. The variables brand trust, brand affect and brand loyalty were defined as reflective variables and were measured through 5 items each, evaluated on 7-points Likert scales, from 1-strongly disagree to 7 -strongly agree. The measures used were individualoriented attitudinal measures. All the brand-related 
measurements were created taking into account the influence of social media marketing communication on consumers' perceptions.

The conceptual model was defined based on the following hypotheses there is a direct and positive effect between:

H1: social media marketing communication and brand trust.

H2: social media marketing communication and brand affect.

H3: brand trust and brand affect.

H4: brand trust and brand loyalty.

H5: brand affect and brand loyalty.

In order to develop the SEM analysis, it was necessary to evaluate the accuracy of the measurements. In this regard it was conducted a reliability analysis based on the internal consistency of measurements, using Cronbach Alpha and composite reliability coefficients [8]. As shown in table 1, all the values of Cronbach Alpha and composite reliability coefficients are above the recommended threshold of 0.7. The Cronbach Alpha coefficients are ranging from 0.828 to 0.932 and the composite reliability coefficients are ranging from 0.866 to 0.948 , proving a very good reliability.

The validity of the measurements was tested using predictive, convergent and discriminant validity. Predictive validity was measured through Q-squared coefficients. As shown in table 1, the values of Q-squared coefficients are ranging from 0.191 to 0.685 and are all above the threshold of 0.1 , proving that the scales used for measuring brand trust, brand affect and brand loyalty have a good predictive capacity.

Table 1. Latent variable coefficients.

\begin{tabular}{|l|c|c|c|c|}
\hline & $\begin{array}{c}\text { SM marketing } \\
\text { communication }\end{array}$ & $\begin{array}{c}\text { Brand } \\
\text { trust }\end{array}$ & $\begin{array}{c}\text { Brand } \\
\text { affect }\end{array}$ & $\begin{array}{c}\text { Brand } \\
\text { loyalty }\end{array}$ \\
\hline $\begin{array}{l}\text { Cronbach's } \\
\text { alpha }\end{array}$ & 0.828 & 0.932 & 0.908 & 0.919 \\
\hline $\begin{array}{l}\text { Composite } \\
\text { reliability }\end{array}$ & 0.866 & 0.948 & 0.932 & 0.940 \\
\hline AVE & 0.399 & 0.786 & 0.732 & 0.757 \\
\hline Q-squared & - & 0.191 & 0.612 & 0.685 \\
\hline R-squared & - & 0.190 & 0.612 & 0.688 \\
\hline
\end{tabular}

The convergent and discriminant validity were determined based on the exploratory and confirmatory factor analysis. Before running the factor analysis, were conducted the Kaiser-Meyer-Olkin and Bartlett tests [9].
The KMO test has a very good value (0.885), above the threshold of 0.5 . Also, the significance value of Bartlett's test is under the threshold of 0.05 , proving that the data are suitable for factor analysis.

All factor loadings for brand trust, brand affect and brand loyalty have values above the threshold of 0.5 and the $p$ values associated with the loadings are under the threshold of 0.05 , fulfilling the conditions of convergent validity. In case of the formative variable, this rule doesn't have to apply.

Analysing the values of average variance extracted (AVE) presented in table 1, it can be seen that all the AVE values registered by the reflective variables are above the threshold of 0.5 and are under the values of the composite reliability coefficients. This also proves that the measurements have a good convergent validity.

The discriminant validity was determined by analysing the correlations among latent variables with squared roots of AVEs, presented in table 2.

Table 2. Correlations among latent variables with squared roots of AVEs.

\begin{tabular}{|l|c|c|c|c|}
\hline & $\begin{array}{c}\text { SM } \\
\text { MarCom }\end{array}$ & $\begin{array}{c}\text { Brand } \\
\text { trust }\end{array}$ & $\begin{array}{c}\text { Brand } \\
\text { affect }\end{array}$ & $\begin{array}{c}\text { Brand } \\
\text { loyalty }\end{array}$ \\
\hline $\begin{array}{l}\text { SM } \\
\text { MarCom }\end{array}$ & $\mathbf{( 0 . 6 3 2 )}$ & 0.404 & 0.461 & 0.405 \\
\hline Brand trust & 0.404 & $\mathbf{( 0 . 8 8 6 )}$ & 0.755 & 0.764 \\
\hline Brand affect & 0.461 & 0.755 & $\mathbf{( 0 . 8 5 6 )}$ & 0.754 \\
\hline $\begin{array}{l}\text { Brand } \\
\text { loyalty }\end{array}$ & 0.405 & 0.764 & 0.754 & $\mathbf{( 0 . 8 7 0 )}$ \\
\hline
\end{tabular}

As it can be seen all the values of squared roots of AVEs are higher than any of the values above or below them, in the same column, proving a good discriminant validity. In conclusion, all the measures used in this model are reliable and valid.

The next step in performing the SEM analysis consisted in determining the path coefficients and the $p$ values for all the relationships included in the conceptual model. In this manner, it is possible to validate the research hypotheses.

The validation of the research hypotheses is possible if the values of the path coefficients are above the threshold of 0.1 and the $p$ values are under the threshold of 0.05 . As it can be seen in Figure 2, all the path coefficients have values above 0.1 , ranging from 0.212 to 0.670 and all the $p$ values are under 0.001 . Therefore, the research hypotheses are validated.

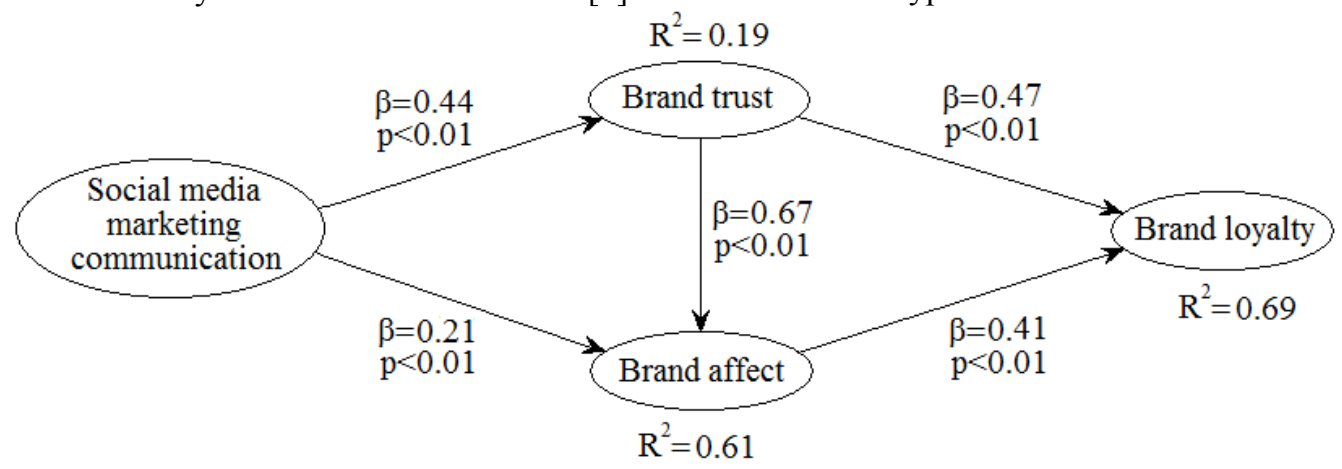

Fig. 2. The validated conceptual model regarding the influence of social media marketing communication on brand trust, brand affect and brand loyalty. 
The R-squared coefficients reflect the percentages of explained variance associated with each latent variables. Therefore, brand trust is explained by the social media marketing communication variable in a proportion of $19 \%$. Brand affect is explained by social media marketing communication and brand trust in a proportion of $61 \%$. Brand loyalty is $69 \%$ explained by brand trust and brand affect.

Table 3. Direct, indirect and total effects among the variables conceptual model regarding the influence of social media marketing communication on brand trust, brand affect and brand loyalty.

\begin{tabular}{|l|l|c|c|c|}
\hline \multicolumn{2}{|c|}{} & $\begin{array}{c}\text { SM } \\
\text { MarCom }\end{array}$ & $\begin{array}{c}\text { Brand } \\
\text { trust }\end{array}$ & $\begin{array}{c}\text { Brand } \\
\text { affect }\end{array}$ \\
\hline \multirow{4}{*}{ Brand trust } & Direct effect & 0.436 & - & - \\
\cline { 2 - 5 } & $\begin{array}{l}\text { Indirect } \\
\text { effect }\end{array}$ & - & - & - \\
\cline { 2 - 5 } & Total effect & 0.436 & - & - \\
\hline \multirow{3}{*}{ Brand affect } & $\begin{array}{l}\text { Indirect } \\
\text { effect }\end{array}$ & 0.292 & - & - \\
\cline { 2 - 5 } & Total effect & 0.504 & 0.670 & - \\
\hline \multirow{3}{*}{$\begin{array}{l}\text { Brand } \\
\text { loyalty }\end{array}$} & Direct effect & - & 0.472 & 0.411 \\
\cline { 2 - 5 } & $\begin{array}{l}\text { Indirect } \\
\text { effect }\end{array}$ & 0.413 & 0.275 & - \\
\cline { 2 - 5 } & Total effect & 0.413 & 0.747 & 0.411 \\
\hline
\end{tabular}

The SEM analysis allows to determine, besides the direct effects among the variables, also the indirect and total effects. As shown in table 3, social media marketing communication has a direct and also an indirect effect (through brand trust) on brand affect. The values of its total effect is 0.504 . Social media marketing communication has a total effect on brand loyalty of 0.413 .

Table 4. Model fit and quality indices.

\begin{tabular}{|c|c|c|}
\hline Indicator & Value & Validation \\
\hline Average path coefficient & $\mathrm{APC}=0.440, p<0.001$ & Yes \\
\hline Average R-squared & $\mathrm{ARS}=0.497, p<0.001$ & Yes \\
\hline Average block VIF & $\mathrm{AVIF}=1.806$ & Yes \\
\hline
\end{tabular}

Also, in order to validate the model, fit and quality indices of the model must be analyzed. In this case, the values of APC and ARS associated probabilities must be $p<0.05$ and the value of AVIF is considered acceptable if $A V I F \leq 5$ and ideally if $A V I F \leq 3.3$. As shown in table 4, the model is validated.

\section{Conclusion}

The most important conclusion that can be drawn is that the proposed conceptual model is validated. The research demonstrated that social media marketing communication has the capacity to influence brand trust and brand affect, the two main determinants of brand loyalty. The model shows that the characteristics of social media marketing communications have a direct effect on brand trust and brand affect. It also demonstrates that brand trust has a direct effect on brand affect and on brand loyalty. Brand affect has also a direct effect on brand loyalty. Therefore, all five research hypotheses were validated.

Understanding the essence of functioning social media and behavior motives and interests of social networking users makes it possible to develop effective mechanisms of influence on the target audience within the framework of the companies' marketing strategy.

Social network is an objective reality of the modern world, since it arose on the basis of the desire of people as social objects to communicate with similar individuals, transformation of society into individuals with an intense rhythm of life that leads to a shortage of time for personal encounters and the existing innovationcommunication technologies. The active use by companies of tools for attracting a target audience on the Internet involves the use of marketing in social networks, which allows to attract a certain number of customers by building specific communications with it [10].

Another important conclusion is that all the measurement scales that were used in this research are valid and the measurements have a good explanatory and predictive capacity. The main limit of this research comes from the fact that the model took into account only the attitudinal aspect of loyalty. Another limit comes from the fact that the sample is not representative at a national level.

Social media marketing involves targeting the target audience through social networks by creating content that matches the interests of a particular user group and fits into the specifics of the functioning of a particular social service. The main goal of the company is to develop an effective strategy that will optimize its activities in the social network, using the best tools for attracting users and building sustainable communication on a long-term basis, with the effective use of available financial and human resources. A company to ensure competitive advantages in social networks should analyze the specified environment and respond promptly to changes in user behavior, the introduction of innovative digital marketing technologies, transformation into relevant services through the implementation of appropriate marketing decisions.

\section{References}

1. Evans, D., McKee, J.: Social Media Marketing: The Next Generation of Business Engagement. Wiley Publishing (2010)

2. Macarthy, A.: 500 Social Media Marketing Tips: Essential Advice, Hints and Strategy for Business Facebook, Twitter, Pinterest, Google+, YouTube, Instagram, LinkedIn, and More! CreateSpace (2018)

3. Jacoby, J., Kyner, D.B.: Brand Loyalty vs. Repeat Purchasing Behavior. J. of Mark. Res. 10, 1-9 (1973)

4. Jacoby, J.: A Model of Multi-Brand Loyalty. J. of Adv. Res. 11(3), 25-31 (1971) 
5. Reto, F.: Multi-brand loyalty: when one brand is not enough. Qualit. Mark. Res.: An Int. J. 17/4, 464-480 (2014)

6. Gray, N., Fox, M.: Social Media Marketing: Step by Step Instructions For Advertising Your Business on Facebook, Youtube, Instagram, Twitter, Pinterest, Linkedin and Various Other Platforms. CreateSpace (2018)

7. Digital Marketing Tutorial. https://www.tutorialspoint.com/digital_marketing/in dex.htm (2019) Accessed 20 Apr 2019

8. Cronbach, L.: Coefficient alpha and the internal structure of tests. Psychometr., 16, 297-334 (1951)

9. Cureton, E.E., D'Agostino, R.B.: Factor analysis: an applied approach. Lawrence Erlbaum Associates, Hillside (1983)

10. Whiting, A., Williams, D.: Why people use social media: a uses and gratifications approach. Qualit. Mark. Res.: An Int. J. 16(4), 362-369 (2013) 